\title{
Performance and emissions of a methane fueled v-twin four stroke spark ignited engine
}

\author{
Daniel John Piekarski, James H. Lee, Robert D. Garrick, Andrew Smith, Kenneth E. Krapf, \\ John Bulzacchelli
}

Rochester Institute of Technology, Rochester, USA

\section{Email address:}

jhleme@rit.edu (James H. Lee), piekarski.daniel@gmail.com (D. J. Piekarski)

\section{To cite this article:}

Daniel John Piekarski, James H. Lee, Robert D. Garrick, Andrew Smith, Kenneth E. Krapf, John Bulzacchelli. Performance and Emissions of a Methane Fueled V-Twin Four Stroke Spark Ignited Engine. International Journal of Energy and Power Engineering.

Vol. 3, No. 1, 2014, pp. 21-27. doi: 10.11648/j.ijepe.20140301.14

\begin{abstract}
This paper discusses the on-going study of a modified two-cylinder V-twin engine used to research and analyze natural gas combustion. The purpose of the experimentation is to determine the feasibility of Natural Gas as an alternative fuel for automotive and stationary power generation applications. During testing the engine was operated under various loads and RPMs. The compression ratio (CR) of the engine was increased from 9.0:1 to 13.8:1 with the expectation of improved fuel combustion and improved emissions. The Exhaust Gas Recirculation (EGR) and air-fuel ratio (AFR) were also varied to determine optimal levels that would improve emissions without compromising excessive power (hp). Lean limit analysis was conducted to understand the effect of increased AFR on combustion and emissions. Results from testing confirmed an emissions benefit of going from low compression to high compression. The Total Hydrocarbons (THC) decreased 25\%, Carbon Monoxide levels decrease by $48 \%$ and the Oxides of Nitrogen (NOx) decreased by 20\%. A low percentage of EGR, between 3-6\%, helped reduce Oxides of Nitrogen $\left(\mathrm{NO}_{\mathrm{x}}\right)$ emissions from over $830 \mathrm{ppm}$ to less than 450 ppm, an improvement of almost $50 \%$, with less than a $2 \%$ increase in THC and CO. Power (hp) actually improved by about $1.5 \%$ with $3 \%$ EGR. Increasing the AFR proved to decrease emissions but at a cost of power and the lean limit of the engine was found to be between 22 and 23 AFR. At 22 AFR the THC emissions decreased by 40\%, CO emission by $90 \%$ and NOx emissions by almost $50 \%$, but the power decreased by over $35 \%$.
\end{abstract}

Keywords: Compressed Natural Gas, Combustion, Emissions, Exhaust Gas Recirculation, Air Fuel Ratio, Compression Ratio

\section{Introduction}

Rising oil prices and a global emphasis on the reduction of pollution has prompted the search for an alternative fuel sources [1-6]. The development of Compressed Natural Gas (CNG) engines is a solution to help alleviate dependence on oil and reduce emissions caused by the transportation sector. Natural gas is one of the most promising alternative fuels and is cheaper and cleaner burning than its gasoline and diesel equivalents [7-9]. Natural gas is also readily available throughout the world [10] with reserves in the U.S. increasing every year since 1999 according to the U.S. Energy Information Administration (EIA) [11].

Although natural gas has a lower energy density than gasoline or diesel, research has shown that a natural gas engine has the potential for increased efficiency and lower emissions [12]. Natural gas has a very high Research Octane
Number (RON) of 130, allowing the engine to be run at higher compression ratios without knocking [13]. Another benefit of natural gas fuel is the lower emissions which is reduced even further through the use of lean burn operating techniques [9].

Lean burn, defined as an Air Fuel Ratio (AFR) that is greater than what is stoichiometric for a given fuel (17.2:1 for $\mathrm{CNG}$ ), also has the advantage of increased thermal efficiency due to an increased ratio of specific heat [14]. Air has a higher ratio of specific heat compared to natural gas (methane) so as more air is added and the mixture of air and fuel becomes leaner, the AFR the ratio of specific heats also increases.

$$
\begin{gathered}
\gamma(\text { Ratio of Specific Heats })=\mathrm{Cp} / \mathrm{Cv} \\
\gamma_{\text {air }}=1.40
\end{gathered}
$$




$$
\gamma \text { Natural Gas (Methane) }=1.32
$$

$\mathrm{CNG}$ is not only a viable alternative fuel for Spark Ignition (SI) applications, but it also has the potential to match the high power density of other fuels with the development of Homogenous Charge Compression Ignition (HCCI) $[10,12,15,16]$. HCCI holds great potential for increasing the energy density and efficiency of natural gas engines. But HCCI engines have been very problematic when implemented for transportation applications. It is very difficult to achieve precise control over the combustion process and maintain the engines efficiency over a wide range of operating conditions with HCCI [12]. For these reasons many of the current developments in HCCI engines have focused on stationary power generation [12, 17].

In this investigation we will be focusing on Spark Ignition (SI) natural gas engines and the feasibility of compressed natural gas as an alternative fuel source for mobile as well as stationary applications. Acquisition and analysis of the engine data will increase understanding of the benefits of CNG as well as provide insight into the combustion phenomenon. Various dynamics of engine performance including Compression Ratio (CR), AFR, Exhaust Gas Recirculation (EGR), RPM and Engine Load will be explored.

\subsection{Goals}

- Operate, analyze and document the operation of the Natural Gas Engine.

- Optimize the engine performance and determine the effects of seven engine parameters including location of peak in-cylinder pressure (PPL), indicated mean effective pressure (IMEP), air fuel ratio (AFR), engine RPM, engine load, and Exhaust Gas Recirculation (EGR).

\subsection{Objectives}

- $\quad$ Reduce engine emissions $\left(\mathrm{CO}, \mathrm{THC}, \mathrm{NO}_{\mathrm{x}}\right)$

- Understand the factors that drive $\mathrm{CNG}$ fueled engine performance and emissions.

- Investigate Lean Limit operation.

\section{Experimental Apparatus}

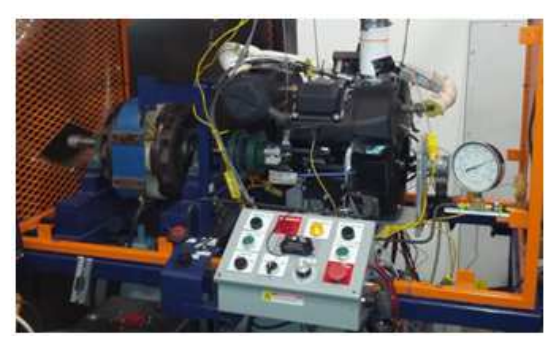

Figure 1. Kohler Command Pro ECH-749 and Test Stand

A modified Kohler Command Pro ECH-749 two-cylinder V-Twin engine with Electronic Fuel Injection (EFI) was used to investigate the capabilities and feasibility of a natural gas engine. The engine was converted from gasoline to $\mathrm{CNG}$. Existing fuel injectors were replaced with prototype Delphi CNG injectors. Higher heat range spark plugs, RC14YC (2 heat ranges higher than stock), were installed and the production Engine Control Unit (ECU) was replaced with a programmable development ECU which could be modified to account for the unique properties of methane fuel. A Delphi linear EGR system was also installed. Table 1 shows detailed specifications of the engine.

Table 1. Engine Specifications

\begin{tabular}{ll}
\hline Base Engine & Kohler Command Pro ECH-749 EFI \\
\hline Type & 2-Cylinder V-Twin \\
Cycle & 4-Cycle \\
Compression Ratio & $13.8: 1$ \\
Displacement & $747 \mathrm{CC}$ \\
Bore/Stroke & $3.27 / 2.72$ in \\
Oil & $5 \mathrm{~W}-30$ Synthetic \\
EGR Valve & Delphi Linear EGR-1 \\
\hline
\end{tabular}

The engine was installed in a GDJ Powertek ${ }^{\circledR}$ Engine test stand consisting of a $30 \mathrm{hp}$ eddy current dynamometer directly coupled to the engine as seen in Figure 1. The dynamometer provides a variable load to the engine that can be manually adjusted via an operator control box. Adjacent to the control box is an engine throttle that is cable driven with a Vernier control. A load cell connected to the dynamometer measures torque (ft-lbs); power can be calculated based on the torque reading and engine speed.

Various modifications were made to the engine test stand including an upgraded Digital-to-Analog Converter (DAC) along with upgraded control and test sensors used for data collection. Kohler's Command Pro EFI engine management system and original engine sensors were used. Combustion data was logged and analyzed with Nation Instruments LabView software along with TFX Engine Technology data loggers and software. A list of test equipment and sensors are listed in Table 2.

Table 2. Supplemental Test Equipment and Sensors

\begin{tabular}{ll}
\hline Mass Air Flow & $\begin{array}{l}\text { Sierra series 620S Fast-Flo Insertion } \\
\text { Flow Meter }\end{array}$ \\
\hline Mass Fuel Flow & $\begin{array}{l}\text { Sierra Smart-Trak 2 Series 100 Flow } \\
\text { Meter }\end{array}$ \\
TFX Data Logger & DBS Basic 5 \\
TFX Sensor Interface Box & SB4/5 \\
Combustion Pressure Sensor & Optrand AutoPSI Pressure Sensor \\
Incremental Rotary Encoder & BEI Model H25 Incremental Encoder \\
O2 Sensor & AEM UEGO Controller \& Bosch LSU \\
Temperature Sensors & 4.2 Sensor \\
\hline
\end{tabular}

Emission testing was conducted with the assistance of Delphi ${ }^{\circledR}$ Inc. using their equipment at their state-of-the-art facility in Rochester, NY. A Horbia Emissions system was used to capture emission data for $\mathrm{NOx}, \mathrm{CO}, \mathrm{CO}_{2}$ and THC. All exhaust emissions were measure using the ISO-certified equipment listed in Table 3. 
Table 3. Delphi Emissions Equipment

\begin{tabular}{ll}
\hline NOx & Chemiluminescents - Horiba CLA-22A \\
\hline $\mathrm{CO}$ & Non-Dispersive Infrared Detector - Horiba AIA-23 \\
$\mathrm{THC}$ & Flame Ionization - Horiba $\quad$ FIA-23A \\
$\mathrm{CO} 2$ & Non-Dispersive Infrared Detector - Horiba AIA-23 \\
\hline
\end{tabular}

After initial testing was completed the compression ratio was increased from 9.1:1 to 13.8:1. High compression pistons (no dome - flat top) were installed, see Figure 2. The production heads were also replaced with high strength steel heads.

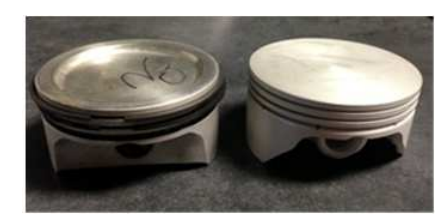

Figure 2. Low Compression vs. High Compression Pistons.

\section{Initial Experimentation}

Initial Testing of the engine was conducted at low compression (9.1:1) for a baseline comparison test of gasoline versus CNG fuel. During testing the engine was operated under various engine loads, RPMs, and Exhaust Gas Recirculation (EGR) percentages. The range of parameters tested are listed in Table 4.

Table 4. Low Compression Testing Parameters.

\begin{tabular}{ll}
\hline RPM & $\mathbf{2 4 0 0 , 3 2 0 0}$ \\
\hline Load (\%) & $25,50,75,100$ \\
EGR (\%) & $1,6,9,12,15,18$ \\
\hline
\end{tabular}

Emissions results in Figure 3 show a comparison of gasoline vs. CNG. The engine was operated at 3200 RPM and maximum load. Emissions, Power, Torque and maximum in-cylinder pressure were recorded. There was approximately a $70 \%$ decrease in NOx emissions while THC and CO both increased. The engine was not calibrated for $\mathrm{CNG}$ fuel during this test so poor fuel combustion may have caused the increase in THC and CO emissions.

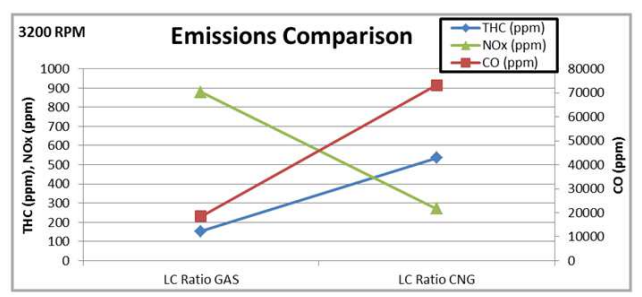

Figure 3. Emissions Comparison of Low Compression Ratio Gasoline and Low Compression Ratio $C N G$.

Combustion results in Figure 4 show a slight decreases in power (hp) and torque (ft. lbs.), about $1 \%$ and $2 \%$ respectively for $\mathrm{CNG}$ compared to gasoline. The results also show an increase in maximum cylinder pressure from 339 to 343 PSI for CNG as compared to gasoline.

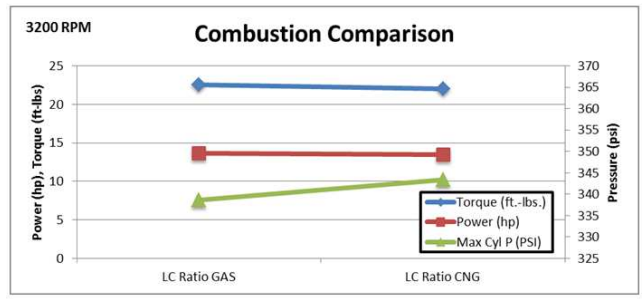

Figure 4. Combustion comparison of Low Compression Ratio Gasoline and Low Compression Ratio CNG.

\section{High Compression Experimentation}

High compression experimentation $(\mathrm{CR}=13.8: 1)$ was conducted using CNG fuel. During testing the engine was operated under various loads, RPMs, EGR percent, and AFR's. In addition, a lean limit analysis was conducted to understand the effects of increased AFR on combustion and emissions.

Table 5. High Compression Testing Parameters.

\begin{tabular}{ll}
\hline RPM & $\mathbf{2 4 0 0 , 3 0 0 0 , 3 2 0 0 , 3 6 0 0}$ \\
\hline Load (\%) & $25,50,75,100$ \\
EGR (\%) & $1,3,6,9,12,15$ \\
AFR & $15,16,17,19,22$ \\
\hline
\end{tabular}

Figure 5 shows an emissions comparison of low compression $\mathrm{CNG}(\mathrm{CR}=9.1: 1)$ to high compression $\mathrm{CNG}$ $(\mathrm{CR}=13.8: 1)$. Results show over a $20 \%$ decrease in $\mathrm{THC}$, about a $48 \%$ decrease in $\mathrm{CO}$ and about a $20 \%$ decrease NOx emissions.

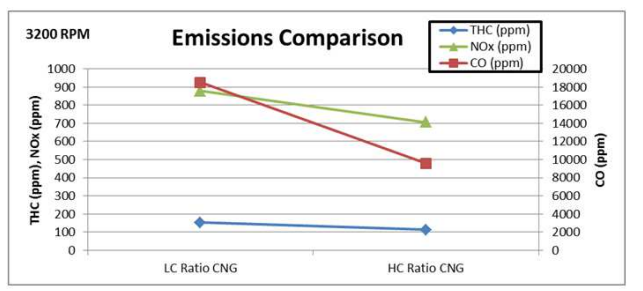

Figure 5. Emissions Comparison of Low Compression Ratio CNG and High Compression Ratio $C N G$.

Figure 6 shows a performance comparison between low compression ratio $\mathrm{CNG}$ to high compression ratio $\mathrm{CNG}$. Results show and increase in power (hp) of $7 \%$, and increase in torque (ft-lbs.) of $8 \%$ and an increase in the maximum cylinder pressure of $8 \%$.

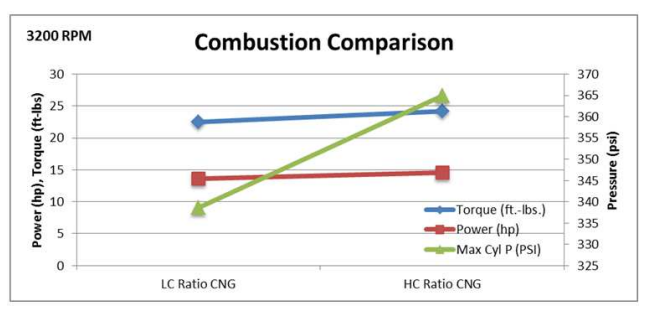

Figure 6. Combustion Comparison of Low Compression Ratio CNG and High Compression Ratio CNG. 


\section{Exhaust Gas Recirculation}

To test the effect of EGR on emissions and combustion the EGR was varied from $0 \%$ to $15 \%$. The equation used to calculate EGR percentage is listed as Equation 4.

$$
\text { Total EGR }=\left(\mathrm{m}_{\text {recycle }} / \mathrm{m}_{\text {cyl tot }}\right)^{*} 100
$$

The amount of EGR is controlled with Delphi Linear EGR-1 Valve. The EGR percentage is based on the mass of exhaust gases recirculated back into the engine. The mass of exhaust gas exiting the engine was measured using the real time measurements produced by the Delphi emissions testing equipment. The Delphi test facility EGR calculation is based on a general combustion equation listed as Equation 5. [18]:

$$
\begin{aligned}
& \mathrm{CH}_{\mathrm{Y}} \mathrm{O}_{\mathrm{Z}}+\mathrm{n}\left(\mathrm{O}_{2}+\varepsilon_{2}\right)+ \\
& \frac{\mathrm{EGR}}{100}\left(\mathrm{aCO}_{2}+\mathrm{bH}_{2} \mathrm{O}+\mathrm{cC}_{3} \mathrm{H}_{3 \mathrm{y}}+\mathrm{dNO}+\mathrm{eH}_{2}+\mathrm{fO}_{2}+\mathrm{gCO}+\mathrm{hN}_{2}\right) \\
\rightarrow & \mathrm{aCO}_{2}+\mathrm{bH}_{2} \mathrm{O}+\mathrm{cC}_{3} \mathrm{H}_{3 \mathrm{y}}+\mathrm{dNO}+\mathrm{eH}_{2}+\mathrm{fO}_{2}+\mathrm{gCO}+\mathrm{hN}_{2}
\end{aligned}
$$

The testing was conducted varying engine load and RPM (see Table 5). Figure 7 shows that when a small percentage of EGR is added, up to $3 \%$, there is a significant drop in NOx emissions and only a slight increase in THC and CO levels. As more EGR was added THC and CO levels start to rise considerably, while NOx levels continue to drop. When the EGR percentage reached over $12 \%$ the engine performance became erratic.

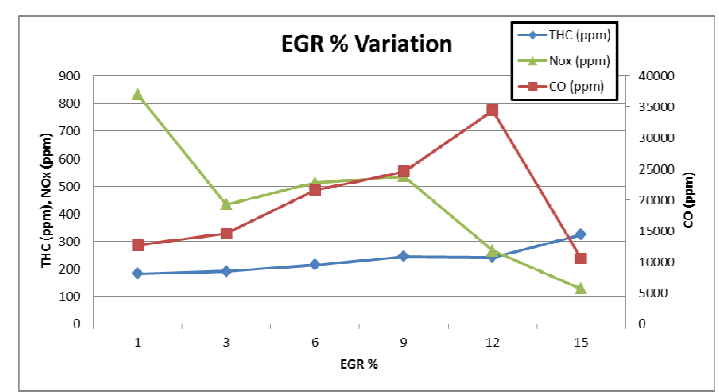

Figure 7. Effect of EGR on Emissions.

Figure 8 shows the effect of EGR on power. Similar to the emissions results, a small percentage of EGR proved to be beneficial, but as more EGR was added the power began to decrease significantly.

\section{Air Fuel Ratio}

Figure 9 shows emissions as a function of the air/fuel ratio. This testing was conducted for the loads and RPMs listed in Table 5. THC levels gradually decreased until reaching a AFR of 19 and then began to increase. CO levels decreased as AFR increased and NOx levels although increasing initially began to drop after reaching an AFR of 17. Further testing of the effect of AFR on emissions was conducted during the lean limit testing and the results are given in Section 7.

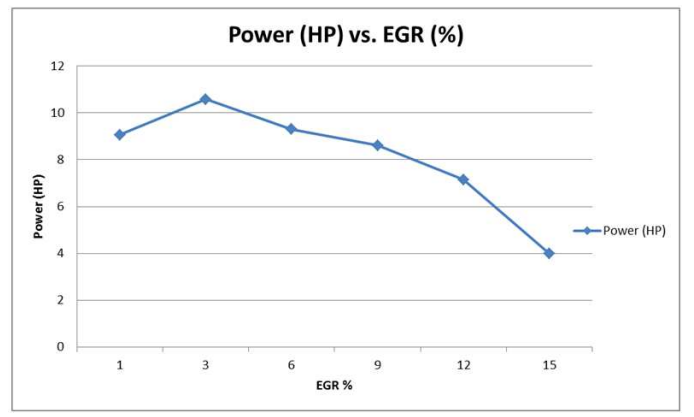

Figure 8. Effect of EGR on Power.

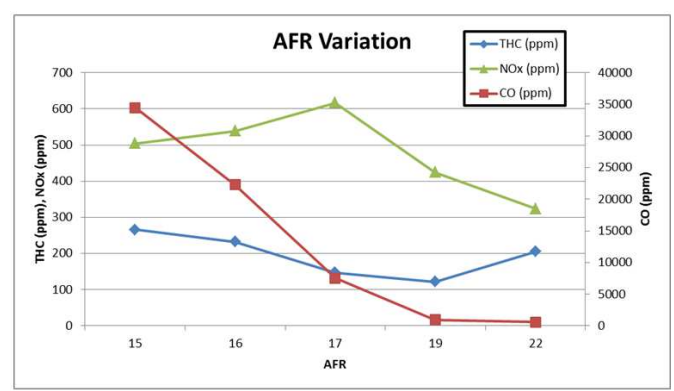

Figure 9. Effect of AFR on Emissions.

Figure 10 shows the effect of AFR on Power. As AFR was increased and the engine was running leaner the power began to drop until an AFR of 22 where the power was approximately $50 \%$ of the maximum.

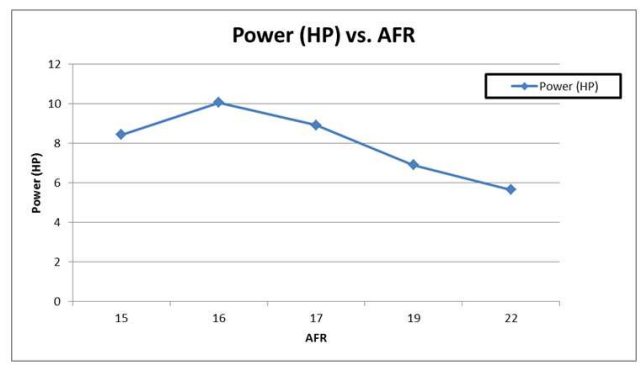

Figure 10. Effect of AFR on Power (hp).

Figure 11 shows the maximum cylinder pressure of both cylinders 1 and 2 as the AFR was increased. Figure 12 shows the IMEP for both cylinders as AFR was increased. Both the maximum cylinder pressure and IMEP decreased as the AFR increased beyond 16 .

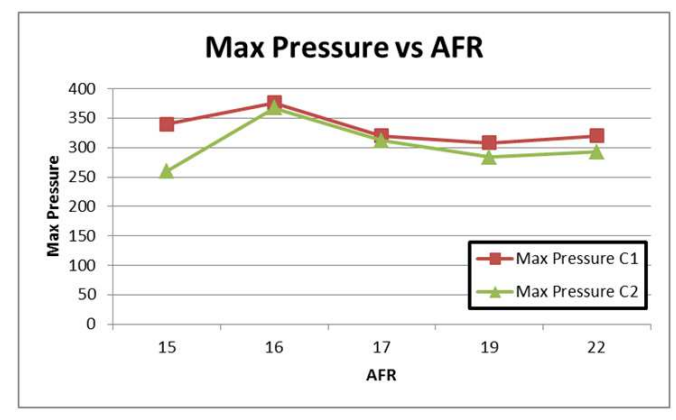

Figure 11: Maximum Cylinder Pressure (PSI) versus AFR. 


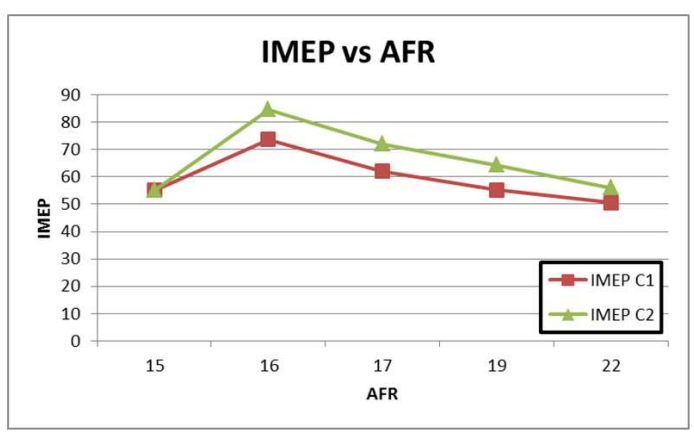

Figure 12. Indicated Mean Effective Pressure versus AFR.

\section{Lean Limit Testing}

The lean limit is defined as the maximum air-fuel ratio where the engine may run without misfiring [19]. Lean limit testing was conducted at the load and RPM points listed in Table 5. The engine ran at the leanest calibration possible at each point and the fuel pressure regulator was used to vary and control the AFR. Running the engine near the lean limit has the potential to significantly reduce emissions, especially that of NOx.

Figure 13 shows the effect of AFR on emissions as the AFR was increased and approached the lean limit. The lean limit was determined to be between 22 and 23 AFR after which the engines performance becomes erratic and unstable. Up to an ARF of $23 \%$ there was a significant improvement in emissions. Results show an exponential decrease in NOx as the engine ran leaner. THC and CO levels also show improvement until reaching the lean limit, after which they begin to increase significantly.

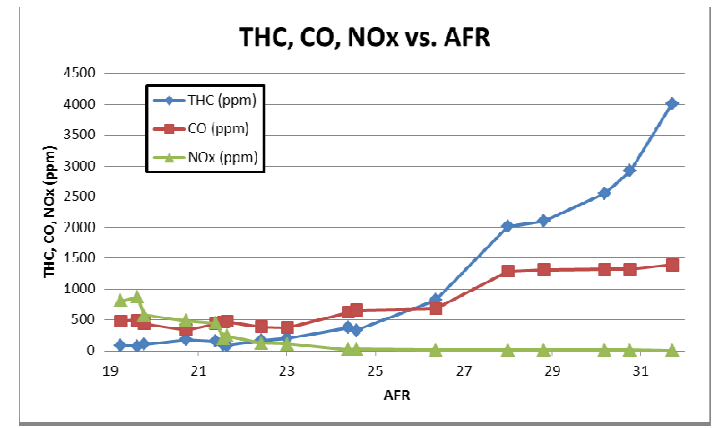

Figure 13. Lean Limit Emissions Results.

Although running lean can greatly benefit emission it does come at a cost. Both Power (hp) and IMEP decreased linearly as show in figures 14 and 15 , respectively.

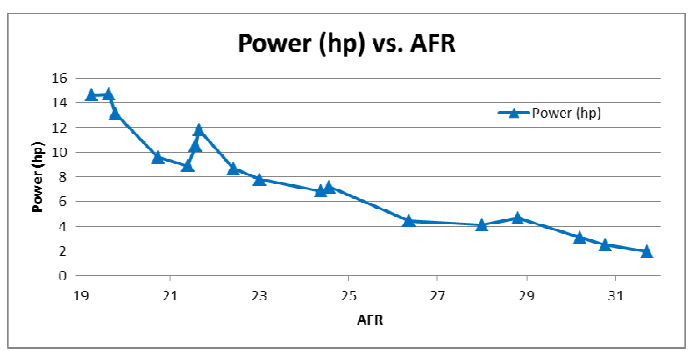

Figure 14. Lean Limit Power Results

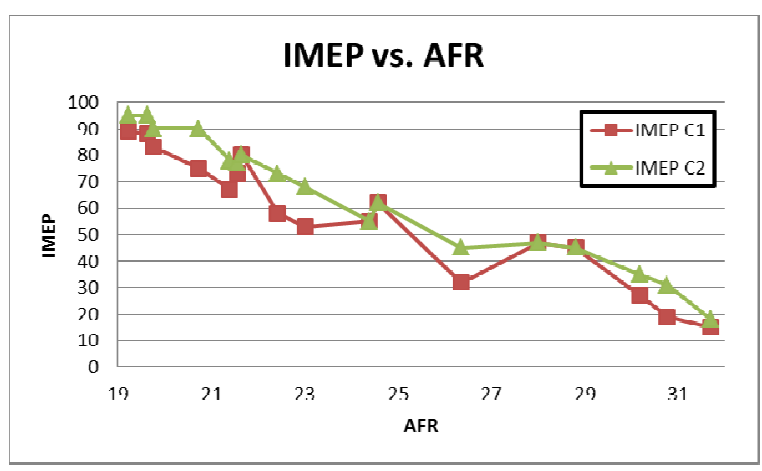

Figure 15. Lean Limit IMEP Results.

Figure 16 shows the IMEP at various AFR levels for both cylinders, cylinder 1 in blue and cylinder 2 in yellow. As the AFR was increased the IMEP began to drop significantly. The data also shows that when the AFR is increased above the lean limit the IMEP became more erratic and there were significant pressure fluctuation between cycles.

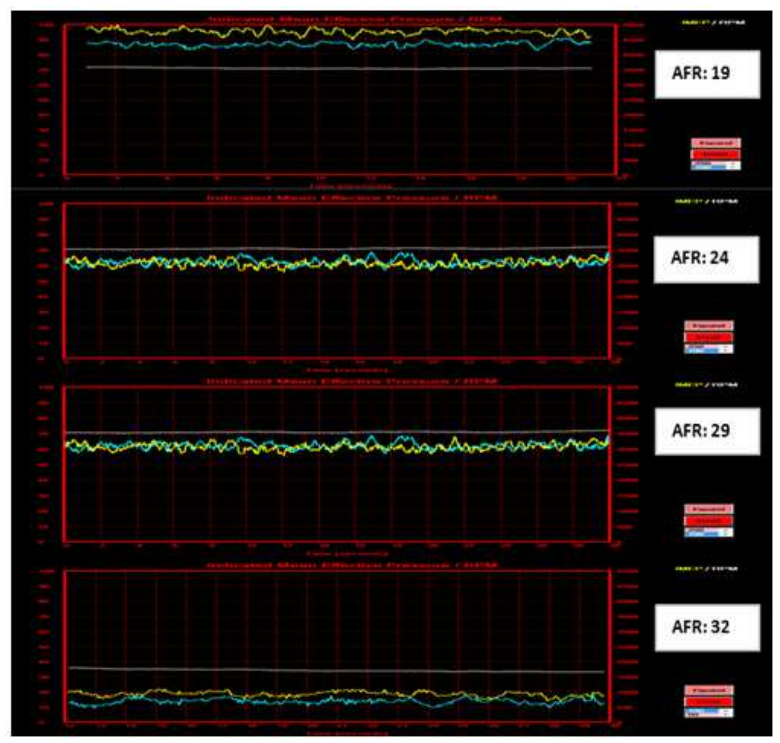

Figure 16. IMEP vs. $A F R$

\section{Conclusions}

A modified two-cylinder V-twin engine was used to analyze natural gas combustion and the resulting emissions. The CR of the engine was increased from $9.0: 1$ to $13.8: 1$ improving the engines performance. During testing the engine was operated under various loads and RPMs. In addition, the Exhaust Gas Recirculation (EGR) percent and the air-fuel ratio (AFR) were also varied. The following conclusions were drawn from this investigation:

- CNG combustion emissions were improved as the compression ratio increased from $9.0: 1$ to $13.8: 1$. The THC decreased by $25 \%$, CO levels decrease by $48 \%$ and the NOx decreased by up to $20 \%$.

- There was a decrease in power produced by the engine when it was fueled with natural gas as compared to gasoline. The baseline test at 3000 RPM, maximum 
load, produced $8 \%$ less power with $\mathrm{CNG}$ as compared to gasoline.

- A low percentage of EGR, between 3-6\%, reduce $\mathrm{NO}_{\mathrm{x}}$ emissions from over $830 \mathrm{ppm}$ to less than $450 \mathrm{ppm}$, with only a $2 \%$ increase in THC and CO. Power (hp) improved by approximately $1.5 \%$ with $3 \%$ EGR, but began to decrease as more EGR was added.

- Running the engine lean proved to substantially improve emissions, but at a cost of power (hp).

- The lean limit of the engine was found to be between 22 and 23 AFR. NOx emissions exponentially decreased as the engine was run leaner. When the lean limit was exceed $\mathrm{THC}$ and $\mathrm{CO}$ levels began to increase significantly.

\section{Future Plans}

This project is an ongoing investigation of Compressed Natural Gas engines. The investigation has shown great potential in $\mathrm{CNG}$ as an alternative fuel to gasoline and diesel fuel and further testing will be conducted.

\subsection{Lean Burn Operation}

The lean limit testing has shown great potential for improving emission and efficiency, further lean limit analysis will be important to better understand the effects of lean burn.

\subsection{Increasing the Compression Ratio}

Higher compression ratio has potential to increase efficiency, improve combustion, and reduce emissions.

\subsection{Spark Advance}

The current ignition timing is not optimal. There is room to improve combustion by advancing the ignition timing. This will help maximize the cylinder pressures and has the potential to improve emissions as well as engine efficiency.

\section{4. $\mathrm{HCCI}$}

Homogenous charge compression ignition has great potential for better emissions and improved engine performance. With an increased compression ratio it may be feasible to reach HCCI with this engine.

\section{Acknowledgements}

The authors would like to thank their sponsors the California Energy Commission under the Energy Innovations Small Grant (EISG) Natural Gas Program and the New York State Energy Research and Development Authority (NYSERDA) for their financial support. The authors would also like to thank their industrial partners Kohler Inc. and Delphi Inc. for their significant contributions.

\section{Nomenclature}

$\begin{array}{ll}\boldsymbol{A F R} & \text { Air/Fuel Ratio } \\ \boldsymbol{C A} & \text { Crank Angle } \\ \boldsymbol{C A D} & \text { Crank Angle Degree } \\ \boldsymbol{C H} 4 & \text { Methane } \\ \boldsymbol{C N G} & \text { Compressed Natural Gas } \\ \boldsymbol{C O} & \text { Carbon Monoxide } \\ \boldsymbol{C O} 2 & \text { Carbon Dioxide } \\ \boldsymbol{C R} & \text { Compression Ratio } \\ \boldsymbol{E F I} & \text { Electronic Fuel Injection } \\ \boldsymbol{E G R} & \text { Exhaust Gas Recirculation } \\ \boldsymbol{I M E P} & \text { Indicated Mean Effective Pressure } \\ \boldsymbol{K} & \text { Kelvin } \\ \boldsymbol{N O} & \text { Nitric Oxide } \\ \boldsymbol{N O \boldsymbol { x }} & \text { Oxides of Nitrogen } \\ \boldsymbol{O 2} & \text { Oxygen } \\ \boldsymbol{P H E} \boldsymbol{V} & \text { Plug-in Hybrid Electric Vehicles } \\ \boldsymbol{P P L} & \text { Location of Peak In-Cylinder Pressure } \\ \boldsymbol{S O C} & \text { Start of Combustion } \\ \boldsymbol{T D C} & \text { Top Dead Center } \\ \boldsymbol{T H C} & \text { Total Hydrocarbons } \\ \boldsymbol{p P m \boldsymbol { M }} & \text { parts per million } \\ \boldsymbol{\gamma} & \text { Ratio of Specific Heats }\end{array}$

\section{References}

[1] Ramadhas AS. Alternative Fuels for Transportation. Boca Raton, FL: CRC Press; 2011.

[2] Shook B. Gas-producing states promoting natural gas vehicles. Natural Gas Week [serial online]. 2011;27:8.

[3] Why Natural Gas-Powered Vehicles? Fleet Maintenance [serial online]. 2012;16:18.

[4] Canakci M, Erdil A, Arcaklioğlu E. Performance and exhaust emissions of a biodiesel engine. Applied Energy. 2006;83:594-605.

[5] Abdullah S., Kurniawan W. H., Khamas M., Ali Y. Emission analysis of a compressed natural gas direct-injection engine with a homogenous mixture. International Journal of Automotive Technology, Vol. 12, No. 1, pp. 29-38 (2011)

[6] Ha, D., Park, J., Yeom, J., Ha, J. et al., "Study on Combustion and Emission Characteristics of CNG Fueled RI-Engine," SAE Technical Paper 2007-01-3621, 2007, doi:10.4271/2007-01-3621. http://papers.sae.org/2007-01-3621

[7] Akansu SO, Dulger Z, Kahraman N, Veziro $\square$ lu TN. Internal combustion engines fueled by natural gas-hydrogen mixtures. International Journal of Hydrogen Energy. 2004;29:1527-1539.

[8] Zeng K, Huang Z, Liu B, et al. Combustion characteristics of a direct-injection natural gas engine under various fuel injection timings. Applied Thermal Engineering. 2006;26:806-813.

[9] S. Rousseau, B. Lemoult, M. Tazerout. Combustion characteristics of natural gas in a lean burn spark-ignition engine. Proceedings of the Institution of Mechanical Engineers, Part D, Journal of Automobile Engineering, 213 (5) (1999), pp. 481-490

[10] Blank, D., "CNG/Methane-Combustion in a Homogeneous-Combustion Radical-Ignition D.I. Diesel Engine," SAE Technical Paper 2007-01-0047, 2007. 
[11] U.S. Energy Information Administration, Natural Gas Explained: What are Proved Reserves?, Aug, 2012.

[12] Kweon C, Pratapas J, Foster D. Homogeneous charge compression ignition ( $\mathrm{HCCI}$ ) engine fueled with natural gas for stationary power generation applications; Proceedings of PWR2006: 2006 ASME Power Conference May 2-4, 2006, Atlanta, Georgia USA

[13] Sen AK, Litak G, Yao B-, Li G-. Analysis of pressure fluctuations in a natural gas engine under lean burn conditions. Applied Thermal Engineering. 2010;30:776-779.

[14] Manivannan, A., porai, P., Chandrasekaran, S., and Ramprabhu, R., "Lean Burn Natural Gas Spark Ignition Engine - An Overview," SAE Technical Paper 2003-01-0638, 2003

[15] Zhao, F., Asmus, T. W., Assanis, D. N., Dec, J. E., Eng, J. A., and Najt, P. M., 2003, "Homogeneous Charge Compression Ignition (HCCI) Engines," SAE Inc., Warrendale, PA, pp.325-342, Chap.4.
[16] Wyszynnski, L., Aboagye, R., Stone, R., and Kalghatgi, G., "Combustion Imaging and Analysis in a Gasoline Direct Injection Engine," SAE Technical Paper 2004-01-0045, 2004.

[17] Flowers, D., 2005, "HCCI-ARICE Natural Gas Engine Development for Stationary Power Applications in California," 2nd Annual Advanced Stationary Reciprocating Engine RD\&D: Moving Forward in Low-Emissions and High-Efficiency Technologies, Diamond Bar, CA.

[18] Müller, M., "General Air Fuel Ratio and EGR Definitions and their Calculation from Emissions," SAE Technical Paper 2010-01-1285, 2010.

[19] Bysveen M. Engine characteristics of emissions and performance using mixtures of natural gas and hydrogen. Energy. 2007;32: 482-489. 